\title{
Influence of Material and Geometrical Properties of Permanent Magnets on Cogging Torque of BLDC
}

\author{
Merve Yildirim \\ Department of Electrical and \\ Electronics Engineering \\ University of Firat \\ Elazig, Turkey \\ merveyildirim@firat.edu.tr
}

\author{
Hasan Kurum \\ Department of Electrical and \\ Electronics Engineering \\ University of Firat \\ Elazig, Turkey \\ hkurum@firat.edu.tr
}

\author{
Damijan Miljavec \\ Department of Electrical \\ Engineering \\ University of Ljubljana \\ Ljubljana, Slovenia \\ damijan.miljavec@fe.uni-lj.si
}

\author{
Selma Corovic \\ Department of Electrical \\ Engineering \\ University of Ljubljana \\ Ljubljana, Slovenia \\ selma.corovic@fe.uni-lj.si
}

\begin{abstract}
Aim of this study is to investigate the influence of both material and geometrical properties of surface mounted permanent magnets (PM) on cogging torque of a brushless DC motor (BLDC) by means of numerical modeling based on finite element method (FEM). To this end, a 2D numerical model of the BLDC motor is built by using the software package Ansys Maxwell. In this study, we analyze the machine properties in no excitation mode (i.e. no stator current is applied) and calculate the distribution of magnetic flux density within the entire motor, the magnetic flux density in the air gap, the cogging torque and the back electromotor force (EMF). Firstly, analysis is performed for four different magnets. It is seen that while cogging torque, back EMF, and magnetic flux density in the air gap for the strongest magnet material have the highest values, the lowest values of these are obtained for the weakest magnet. In the second part of the study, the effect of variation of magnet geometry on the cogging torque, magnetic field density and back EMF of BLDC is examined. Three magnet embrace values are handled in this study. When the magnet embrace increases, the value of the cogging torque reduces. Besides, the maximum values of the back EMF are approximately the same for different magnet embraces, while shapes of the back EMF only change based on the magnet embrace. According to the results, the cogging torque strongly depends on the material and geometrical properties of the magnets.
\end{abstract}

Keywords-BLDC; cogging torque; ansys maxwell; finite element method

\section{INTRODUCTION}

Permanent Magnet Brushless DC (PM BLDC) motors are widely used in different industrial applications such as automotive industry, robots, air conditioners etc. [1,2]. BLDC motors have important advantages such as small size, high reliability, high efficiency and power density because of not having rotor winding and rotor copper losses, faster response, and low maintenance cost due to not having brushes [3-8]. On the other hand, they have some drawbacks such as complex control technique, torque pulsation, vibration, and noise. The torque pulsation occurs due to the cogging torque $[1,9]$. Namely, when the rotor rotates, cogging torque is observed because of the different reluctances created by interaction of the rotor magnets and the stator configuration [10]. This may cause undesirable noise and vibration in PM BLDC motors. It is therefore of outmost importance to reduce or minimize the cogging torque.

Design strategies for cogging torque reduction include magnet shape optimization, fractional slot/pole design, control techniques of the excitation currents etc. [1]. Numerous studies have approached the problem of the cogging torque by using numerical modeling in combination with different optimization methods. For example, in [1] optimum BLDC motor was designed for minimum torque pulsation using finite element modeling and particle swarm optimization methods. The effect of convenient number of magnet poles and stator slots was examined and it was observed that the obtained structure minimized the cogging torque and torque pulsation. In [11], the dynamic behavior of BLDC motor and the effect of magnet embrace on the resulting torque characteristic were investigated by using particle swarm optimization and imperialist competitive algorithm. A detailed study of optimal rotor designs by optimization of magnet embrace and thickness values was performed in [12]. Authors in [13] investigated the effects of different magnet embraces on motor efficiency and cogging torque of PM BLDC motor by using genetic algorithm based optimization. In [14], new design models were examined for reducing the cogging torque of PM BLDC motor. It was observed that the cogging torque obtained from parallel magnetization was smaller than that of radial magnetization. Authors in [15] explained the analysis of interior-type PM BLDC motor with 24-slot for reduction of the cogging torque causing torque ripple. By changing some physical parameters including magnet arc, slot openings, bifurcated slot teeth, and hole types, PM BLDC motor was analyzed. The results showed that the cogging torque and torque ripple reduced and the average torque remained in $1 \%$ range. In [16], analysis of BLDC motor design was realized to be used in unmanned aerial vehicle hybrid drive. By selecting permanent magnets optimum pole arcs, the effect on the cogging torque, electromagnetic torque, induced voltage and circulating currents occurred by the result of the assumed configuration of stator windings. The current waveforms, voltages, and the electromagnetic torque were given for a selected motor working point. The effect of rotor magnet pole arc on the 
cogging torque of PMSM was examined in [17]. The parameters and material properties of external rotor PMSM having three-phase, 12 slot and 8 poles were analyzed in 2D FEM using OPERA. The influence on the phase back EMF produced by the PMSM was also explained. A lower cogging torque means more sinusoidal phase back EMF waveform. It was seen that the magnet pole arc had an important role in the reduction of the cogging torque and lower torque ripple was obtained by decreasing the magnet pole arc. Design and analysis of an axial flux PM motors were explained in [18]. Firstly, the cogging torque was calculated without FE analysis. Then, it was minimized by skew angle and this value was validated by $\mathrm{FE}$ analysis and experimental studies. Authors in [19] explained rotor shape optimization of interior PM BLDC motor based on the magnetization direction to maximize back EMF. FEM analyses for four different models of general magnet shapes were realized for four magnetization directions. As an initial model, the best magnet shape and magnetization direction were chosen for optimization. Then, optimization of the motor was carried out to obtain maximum back-EMF and minimum cogging torque. The optimized design was validated by the experimental studies on a manufactured motor. The influence of pole embrace on the cogging torque and unbalanced magnetic forces of BLDC motors with 14 poles and 12 slots used in the submarines was examined in [20]. The cogging torque and unbalanced magnetic forces in BLDC motors cause acoustic noise. Hence, the cogging torque should be minimized. Cogging torque was calculated for different pole embraces by using FEM. The optimal pole embrace to reduce the cogging torque and unbalanced magnetic forces was obtained.

As observed in the literature, the studies on reducing the cogging torque have been commonly realized by using different optimization methods. In this study, the influence of both material and geometrical properties of the surface mounted PMs on the cogging torque, back EMF and distribution of magnetic flux density B of BLDC motor are separately examined. Besides, while stator windings have been generally supplied with excitation current in the other studies, the difference in this work is that no current has been applied to the windings and only the excitation from the magnets is taken into account. 2D finite element based numerical model of surface mounted PM BLDC motor is built and analyzed in Ansys Maxwell Software. Firstly, the analysis for four different magnet types, namely Alnico5, Ceramic5, SmCo28, and $\mathrm{NdFe} 35$ is performed for the same rotor and stator geometry. In the second part of the study, the influence of magnet geometry on the cogging torque, back EMF and distribution of $\mathrm{B}$ is examined by investigating three different magnet embraces (i.e. $0.833,0.625$, and 0.416 ). In this case, the stator geometry and material properties of magnets are kept constant. Finally, the results of the study are compared to the literature.

\section{DEFINITION OF MOTOR GEOMETRY AND METHODS}

In this study, a BLDC motor with 4 poles, 3 phases and 24 slots with surface mounted permanent magnets on the rotor was studied. We analyzed the motor properties in two dimensions. BLDC motor geometry and assignment of the excitations to the coils are shown in Figure 1. Following output physical quantities were calculated and analyzed: cogging torque, back EMF in stator windings and magnetic flux density. Distribution of magnetic flux density within the entire motor was firstly calculated and visualized. Absolute value and normal and radial components of the magnetic flux density in the center of the air gap were also calculated. Motor parameters used in design are given in Table I.

TABLE I. MOTOR DESIGN PARAMETERS

\begin{tabular}{|c|c|c|}
\hline $\mathbf{N}_{\text {pole }}$ & Total number of poles & 4 \\
\hline $\mathbf{R}_{\text {sh }}$ & Radius of shaft & $9.003 \mathrm{~mm}$ \\
\hline $\mathbf{R}_{\mathbf{r}}$ & Radius of rotor & $25.154 \mathrm{~mm}$ \\
\hline $\mathbf{W}_{\mathbf{g}}$ & Width of airgap & $0.503 \mathrm{~mm}$ \\
\hline $\mathbf{L}_{\mathbf{m a g}}$ & Length of magnet & $6.987 \mathrm{~mm}$ \\
\hline $\mathbf{R}_{\mathbf{s o}}$ & Outer radius of stator & $48 \mathrm{~mm}$ \\
\hline $\mathbf{N}_{\text {slot }}$ & Number of stator slots & 24 \\
\hline $\mathbf{W}_{\text {st }}$ & Width of stator tooth & $2.76 \mathrm{~mm}$ \\
\hline SD & Depth of stator slot & $12.07 \mathrm{~mm}$ \\
\hline
\end{tabular}

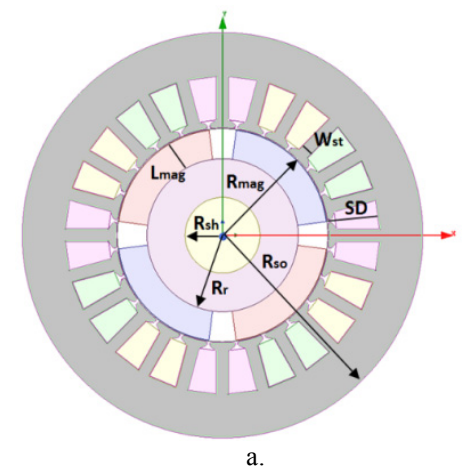

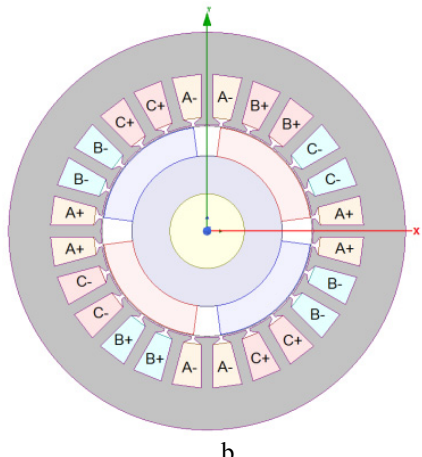

b.
Fig. 1. a. BLDC motor geometry, b. Assignment of the excitations to the coils

In the BLDC motor model, back EMF and torque are given as functions of rotor position [2]. Armature winding and torque equations are used in the motor model. The voltage equations within the armature windings can be defined by (1), (2) and (3):

$$
\begin{aligned}
& V_{A}=R I_{A}+L \frac{d i_{A}}{d t}+E_{A} \\
& V_{B}=R I_{B}+L \frac{d i_{B}}{d t}+E_{B} \\
& V_{C}=R I_{C}+L \frac{d i_{C}}{d t}+E_{C}
\end{aligned}
$$

where $V_{a}, V_{b}$ and $V_{c}$ are the supplied voltages to each phase (A, $\mathrm{B}, \mathrm{C}), R$ is armature winding resistance, $I$ is phase current, $L$ is inductance and $E$ is back EMF. As the rotor position changes, variable magnetic field is obtained and this causes induced EMF [15]. Thus, the magnetic field affects the produced back EMF. Back EMF E can be explained from Faraday's law:

$$
E=-N \frac{d \varphi}{d t}
$$

where $N$ is the number of the turns, $\varphi$ is the flux linkage, and $t$ is time. There is a $120^{\circ}$ angle between the first harmonics of back EMF of each phase as described with (5), (6) and (7) 


$$
\begin{aligned}
& E_{A}(t)=K_{E_{I}} \sin (\omega t) \\
& E_{B}(t)=K_{E_{I}} \sin \left(\omega t-\frac{2 \pi}{3}\right) \\
& E_{C}(t)=K_{E_{I}} \sin \left(\omega t+\frac{2 \pi}{3}\right)
\end{aligned}
$$

where $K_{E l}$ is back EMF first harmonic amplitude [2]. When the rotor rotates, the change of the reluctance in the air gap due to the slots causes the cogging torque. The cogging torque can be calculated from the stored energy in the air gap as follows [19]:

$$
T_{\operatorname{cog}}=-\frac{d W}{d \theta}
$$

where $W$ is the stored energy, $\theta$ is the angular rotor position and $T_{c o g}$ is the cogging torque produced by magnet excitation. The $T_{c o g}$ is expressed in detail by (9):

$$
T_{c o g}=-0.5\left(\Phi_{g}^{2}\right) \frac{d R_{m}}{d \theta}
$$

where $\Phi_{\mathrm{g}}$ is the flux of the air gap and $R_{m}$ is the magnetic reluctance [1]. Since in this study the current $I$ was 0 A, only the back EMF and cogging torque were calculated and analyzed. The back EMF was calculated by applying the constant speed and the number of turns per coil as $500 \mathrm{rpm}$ and 20 turns respectively. The calculation of the cogging torque was performed by applying one mechanical degree angular rotation. Automatic finite element mesh is generated in all models.

\section{DEFINITION OF MATERIAL PROPERTIES}

In this work, stainless steel is used as BLDC shaft material and cooper is selected for the windings. The material properties of magnets, shaft and windings are taken from the Ansys Maxwell library. The B-H curve of the ferromagnetic is manually imported into the software. The B-H curve of the ferromagnetic material used for the rotor and stator core is given in Figure 2. The saturation point for this material is set at $\mathrm{B}=1.7 \mathrm{~T}$. The $\mathrm{B}-\mathrm{H}$ curves for four different magnets used in this study, namely Alnico5, Ceramic5, $\mathrm{SmCo} 28$, and $\mathrm{NdFe} 35$ are given in Figure 3. As shown in Figure 3, the permanent magnetic flux density $B_{r}$ values for Alnico5, Ceramic5, SmCo28, and $\mathrm{NdFe} 35$ are $1.26 \mathrm{~T}, 0.395 \mathrm{~T}, 1.07 \mathrm{~T}, 1.23 \mathrm{~T}$, respectively. The values of coercitive force $H_{c}$ for these magnets are $-50.9295,-190.986,-820.000,-890.000 \mathrm{kA} / \mathrm{m}$, respectively.

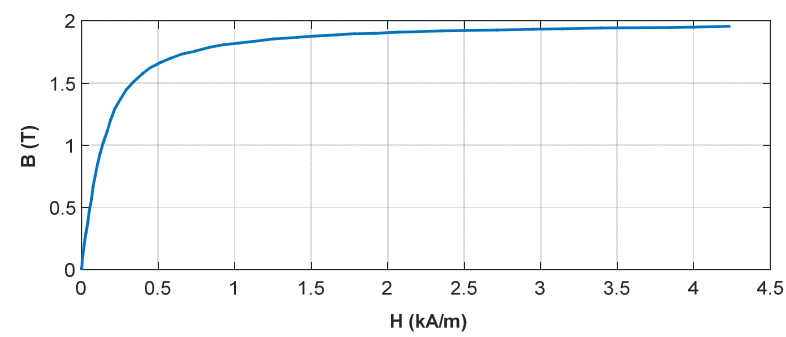

Fig. 2. The B-H curve of the ferromagnetic material used for the stator and rotor core

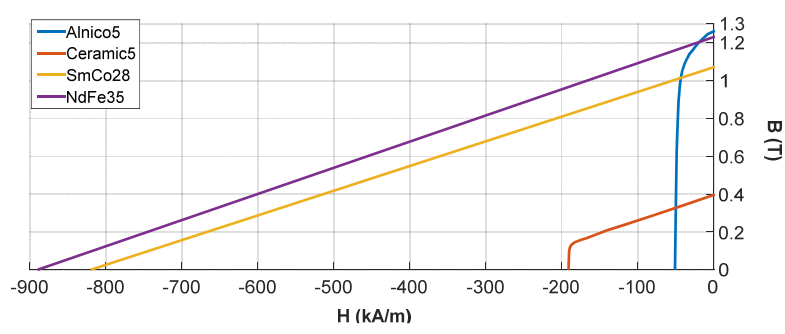

Fig. 3. B-H curves of permanent magnet materials

\section{DEFINITION OF MAGNET EMBRACE}

Magnet embrace is defined as the ratio of rotor pole pitch to the pole arc in PM machines, which can be expressed by

$$
\text { Embrace }=\frac{\beta}{\gamma}
$$

where $\gamma$ and $\beta$ are rotor pole pitch and pole arc of the PM, respectively [11]. Magnet embrace is shown in Figure 4. It has already been shown that the cogging torque can be successfully reduced by the optimum selection of the magnet embrace [12]. In this study, three different magnet embrace values namely $0.416,0.625$, and 0.833 are investigated as ilustrated in Figure 5.

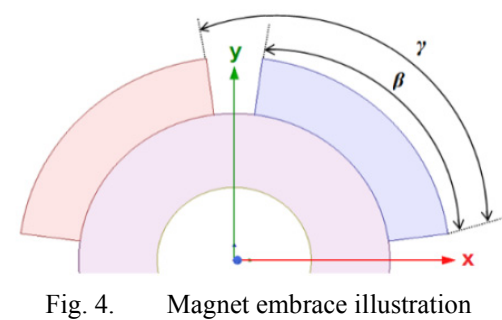

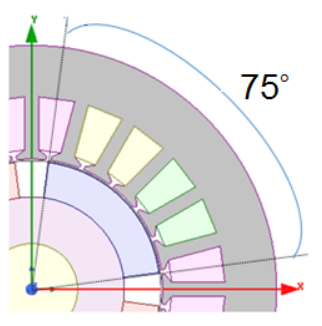

a. b.
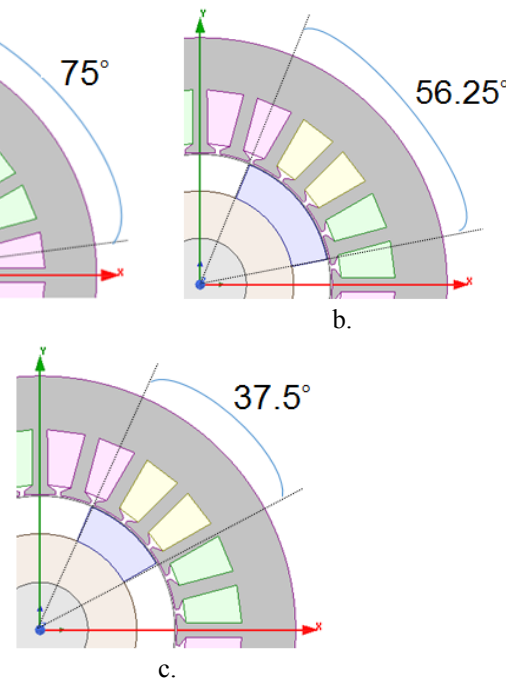

Fig. 5. The BLDC geometries of different magnet embraces investigated in this study: a. the reference magnet embrace 0.833 , b. magnet embrace 0.625 , and c. magnet embrace 0.416 . 


\section{RESULTS AND DISCUSSIONS}

\section{A. Influence of Magnet Type on the BLDC Properties}

By using the reference geometry of the motor which is magnet embrace 0.833 as shown in Figure $5 \mathrm{a}$, the results for different magnet types are given in this subsection. Firstly, the distributions of magnetic flux density $\mathrm{B}[\mathrm{T}]$ in the BLDC calculated for Alnico5, Ceramic5, SmCo28, and $\mathrm{NdFe} 35$ are compared in Figures 6a, 6b, 6c, 6d respectively. The highest B is obtained in Figure $6 \mathrm{~d}$, due to the fact that the strongest magnet NdFe35 is used (B-H curve in Figure 3). The lowest B is obtained with the weakest magnet Ceramic5 as shown in Figure $6 \mathrm{~b}$. Figure $6 \mathrm{~b}$ also shows that the saturation within the stator is not exceeded and the B is somewhat low, while the saturation point is exceeded in Figures $6 \mathrm{a}, 6 \mathrm{c}$ and $6 \mathrm{~d}$ and the B is too high. This means that that the magnets should be properly selected and adjusted to the stator and rotor machine geometry and to the material properties of the machine. The calculated absolute values of $|\mathrm{B}|$ in the airgap are compared for different magnet materials using the reference magnet embrace 0.833 in Figure 7. The normal and tangential components Btan and Bnormal are also shown in Figure 8 separately for each magnet. The highest value of $|\mathrm{B}|$ in the air gap is found for $\mathrm{NdFe} 35$ magnet, while the weakest one is obtained for Ceramic5. Comparison of the cogging torque and the back EMF for different magnet materials using the reference magnet is shown in Figures 9 and 10 respectively.

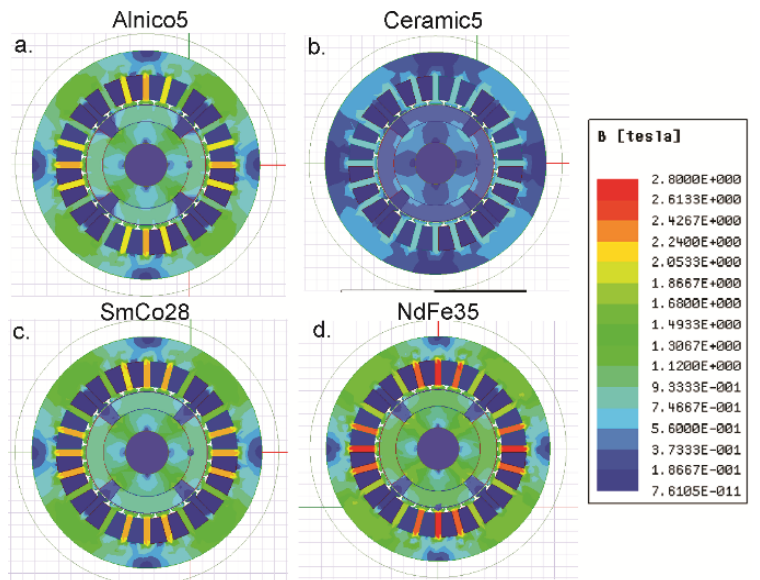

Fig. 6. The distribution of $\mathrm{B}$ in the machine for different magnet materials using the reference magnet embrace 0.833

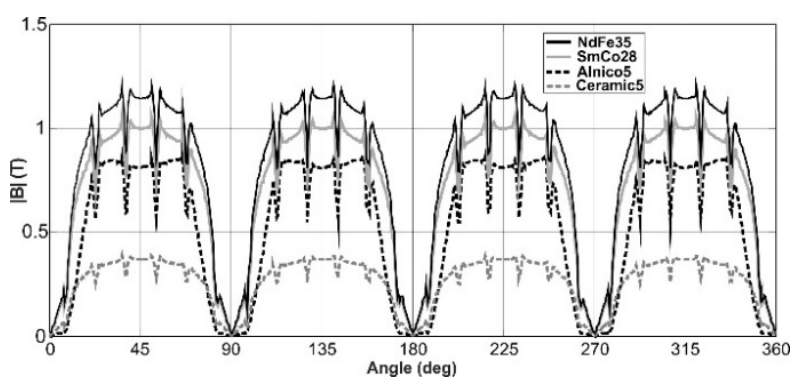

Fig. 7. Comparison of $|\mathrm{B}|$ in the airgap for different magnet materials using the reference magnet embrace 0.833

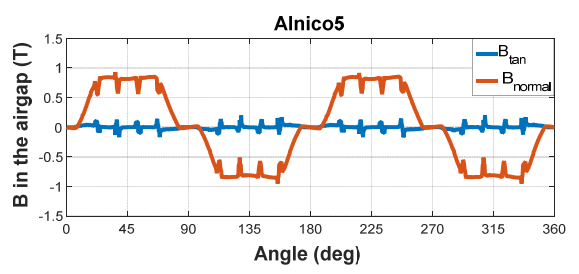

Ceramic5

b.

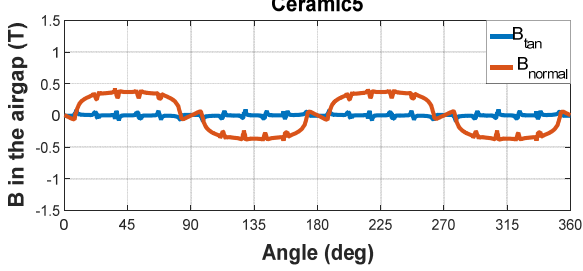

SmCo28

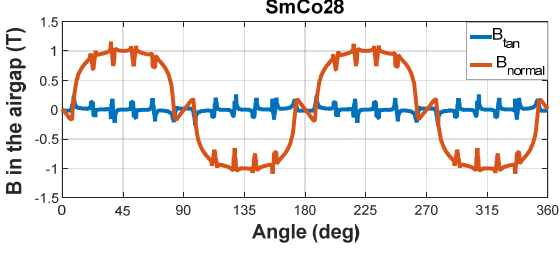

NdFe35

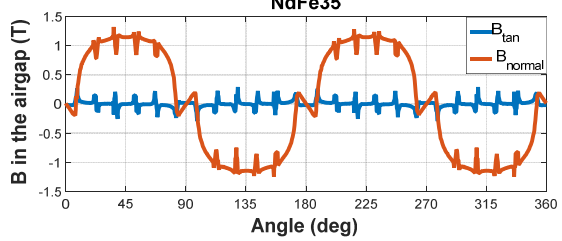

Fig. 8. Comparison of B components in the air gap for different magnet materials using the reference magnet embrace 0.833

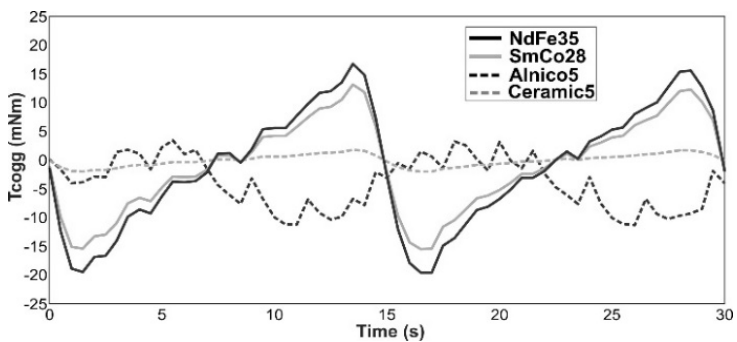

Fig. 9. Comparison of the cogging torque for different magnet materials using the reference magnet embrace 0.833

The normal and tangential components $B_{\text {tan }}$ and $B_{\text {normal }}$ are also shown in Figure 8 separately for each magnet. Results in Figures 9 and 10 show that cogging torque and back EMF for the strongest magnet material $(\mathrm{NdFe} 35)$ have the highest peak to peak values which are $33.332 \mathrm{mNm}$ and $23.948 \mathrm{~V}$, respectively. On the contrary, the lowest peak to peak values are obtained for the weakest magnet, Ceramic5, as $17.752 \mathrm{mNm}$ and $7.702 \mathrm{~V}$, respectively. The curves for Alnico5 differ from the ones for the other materials due to different B-H characteristic shown in the Figure 3. The nonsymetries present in the curves of $T_{\text {cogg }}$ in Figure 9 are related to the finite element mesh quality. It can also be observed that while B in the airgap is high, the cogging torque and back EMF will also be high. Therefore, the highest value of the cogging torque and the back EMF are for NdFe35 magnet, while the lowest values of the cogging torque and the back EMF are obtained for 
Ceramic5 using the same magnet embrace as shown in Figures 7, 8,9 and 10 .

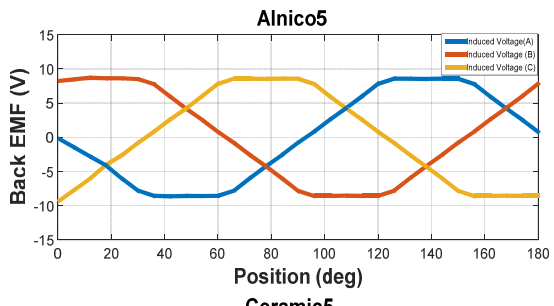

Ceramic5

b.

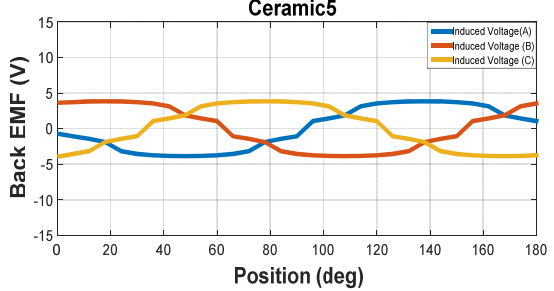

$\mathrm{SmCo28}$

c.

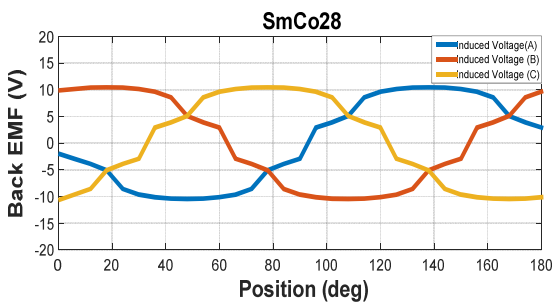

$\mathrm{NdFe} 35$

d.

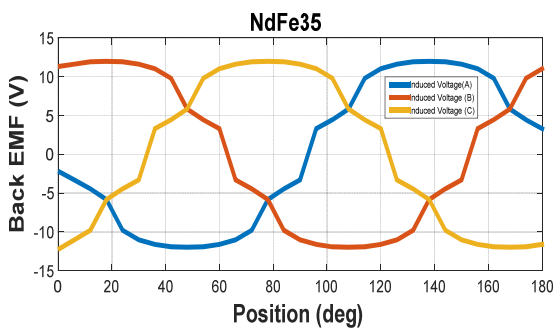

Fig. 10. Comparison of back EMF for different magnet materials using the reference magnet embrace 0.833

B. Influence of Magnet Embrace on the Cogging Torque, $B$ in the Airgap, and Back EMF of BLDC

In this subsection, the results of numerical analysis for three different magnet embraces such as $0.833,0.625$, and 0.416 are shown and discussed. Ceramic5 magnet is used for all examined magnet embraces. $|\mathrm{B}|$ in the airgap are compared for different magnet embraces using Ceramic5 magnet in Figure 11. As seen in Figure 11, maximum values of $|\mathrm{B}|$ remain the same, while the width of the curves increases as the magnet embraces increase. The $B_{\text {tan }}$ and $B_{\text {normal }}$ components are given in Figure 12a, 12b, 12c separately for each magnet embrace. The maximum values of $B_{\text {tan }}$ and $B_{\text {normal }}$ components in the airgap are the same for different magnet dimensions, however, the width of the curve only changes. Calculated cogging torque and back EMF are compared for different magnet embraces in Figures 13 and 14 respectively. Figure 13 shows that the cogging torque value is the highest for the smallest magnet embrace (0.416) due to the highest reluctance change. As the magnet embrace increases, the value of the cogging torque decreases, which is in agreement with the literature data [13]. As shown in Figure 14, the maximum values of the back EMF are almost the same for different magnet embraces, while the shapes of the back EMF are significantly different.

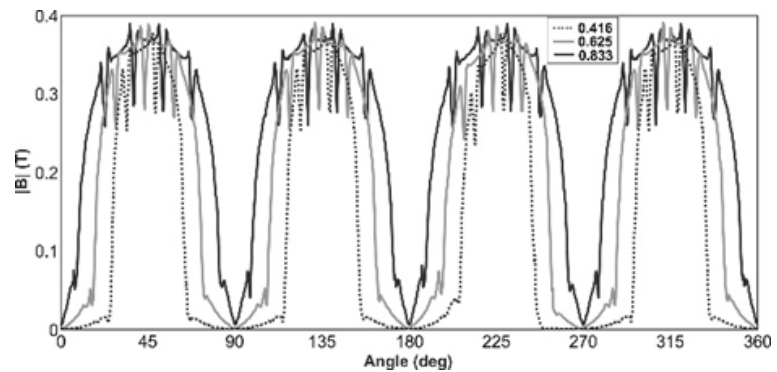

Fig. 11. Comparison of $|\mathrm{B}|$ in the air gap for Ceramic5 magnet material using three different magnet embraces

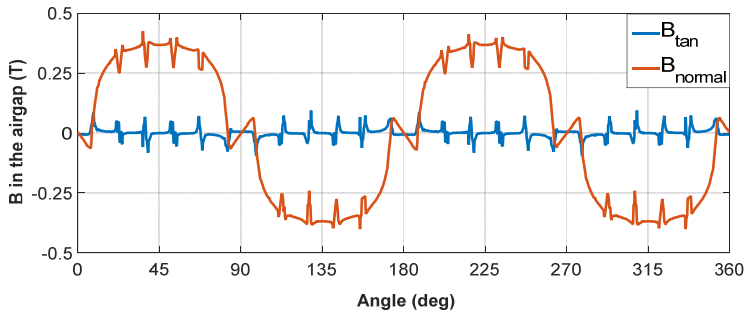

b.
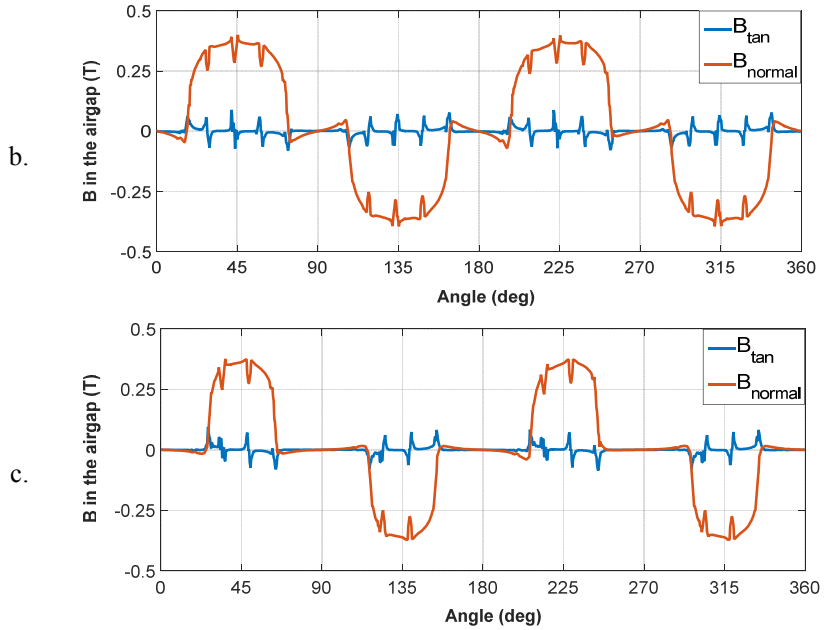

Fig. 12. Comparison of B components in the air gap for magnet embraces a. 0.833 , b. 0.625 c. 0.416 of Ceramic 5 magnet

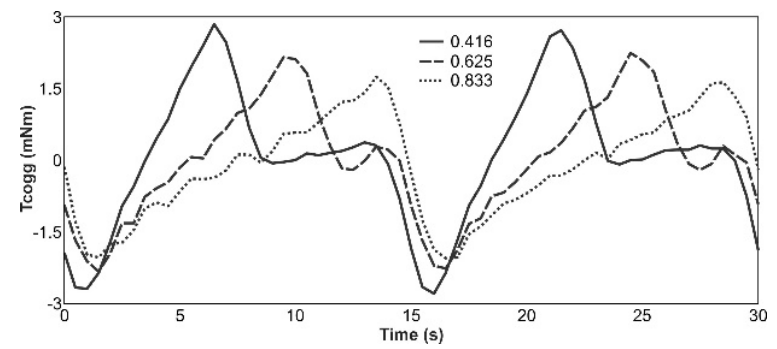

Fig. 13. Comparison of $\mathrm{T}_{\text {cogg }}$ for different magnet embraces 

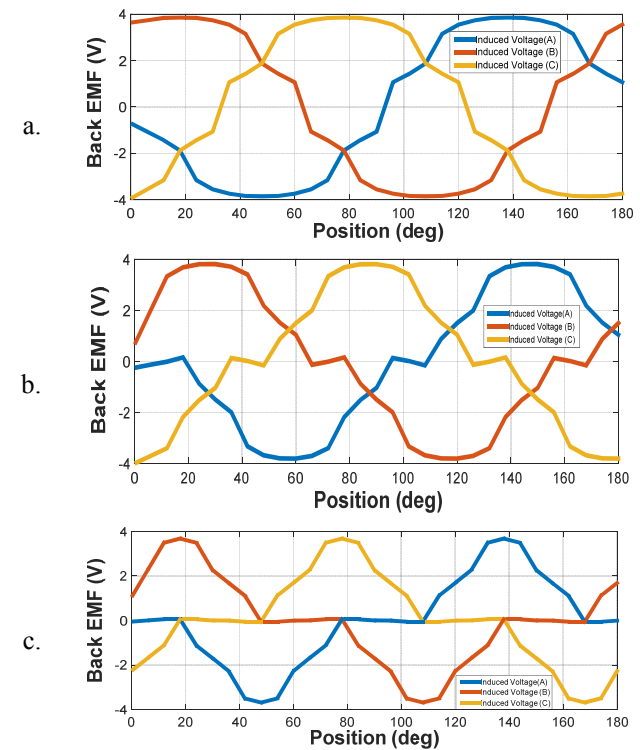

Fig. 14. Comparison of back EMF for different magnet embraces

\section{CONCLUSIONS}

In this paper, the effects of material and geometrical properties of magnets on the cogging torque, back EMF, and distribution of the magnetic flux density of the modeled PM BLDC motor are examined and the motor is successfully analyzed by using Ansys Maxwell Software without applying any current to the stator windings. Firstly, the influence of four magnet materials on the cogging torque, back EMF, and $\mathrm{B}$ in the air gap is examined by using the reference magnet embrace 0.833. It is seen that the highest cogging torque is obtained with the strongest magnet, while the lowest cogging torque is obtained with the least stronger magnet (Ceramic5). Besides, B is somewhat low when using Ceramic5 magnets, while the $\mathrm{NdFe} 35$ magnet results in an excessively high $\mathrm{B}$. The effect of magnet embrace on the cogging torque is handled. It is observed that while magnet embrace increases, cogging torque decreases. However, maximum values of the back EMF are almost the same for different magnet embraces, while the shapes of the back EMF vary. Furthermore, maximum value of $|B|$ in the air gap remains the same, when the curve width increases as the magnet embrace increases. As seen from the results, to obtain the optimum properties of BLDC such as B below the saturation point, minimum cogging torque and adequate shape of back EMF, the rotor and stator geometry have to be properly designed and adequate materials selected according to the motor geometry and its material properties.

\section{REFERENCES}

[1] M. Pourjafari, E. F. Choolabi, M. J. Bolan, "Optimum design of brushless DC motor with minimum torque pulsation using FEM and PSO", AUT Journal of Electrical Engineering, Vol. 44, No. 2, pp. 59-70, 2012

[2] Y. S. Jeon, H. S. Mok, G. H. Choe, D. K. Kim, J. S. Ryu, "A new simulation model of BLDC motor with real back EMF waveform", 7th Workshop on Computers in Power Electronics, Blacksburg, USA pp. 217-220, July 16-18, 2000
[3] M. Yildirim, M. Polat, H. Kurum, "A survey on comparison of electric motor types and drives used for electric vehicles", 16th International Power Electronics and Motion Control Conference and Exposition, Antalya, Turkey, pp. 218-223, September 21-24, 2014

[4] S. M. Jang, H. W. Cho, S. K. Choi, "Design and analysis of a high-speed brushless DC motor for centrifugal compressor", IEEE Transactions on Magnetics, Vol. 43, No. 6, pp. 2573-2575, 2007

[5] P. Bajec, B. Pevec, D. Miljavec, "Optimal control of brushless PM motor in parallel hybrid propulsion system", Mechatronics, Vol. 20, No. 4, pp. 464-473, 2010

[6] R. N. Nanekaran, E. F. Chulabi, "Shape optimization of the permanent magnet pole of the brushless DC motor by FEM", Electrical Power Engineering Frontier, Vol. 3, No. 3, pp. 16-24, 2014

[7] A. Saygın, C. Ocak, A. Dalcali, E. Celik, "Optimum rotor design of small PM BLDC motor based on high efficiency criteria", ARPN Journal of Engineering and Applied Sciences, Vol. 10, No. 19, pp. 91279132, 2015

[8] C. Ocak, I. Tarımer, A. Dalcali, D. Uygun, "Investigation effects of narrowing rotor pole embrace to efficiency and cogging torque at PM BLDC motor", TEM Journal, Vol. 5, No. 1, pp. 25-31, 2016

[9] J. G. Kim, H. G. Kim, I. D. Kim, "Program architecture for realizing design optimization of a BLDC motor", 7th International Conference on Power Electronics and Drive Systems, Bangkok, Thailand, pp. 893-896, November 27-30, 2007

[10] K. J. Kang, G. H. Jang, S. J. Sung, "Frequency characteristics of BEMF, cogging torque and UMF in a HDD spindle motor due to unevenly magnetized PM", IEEE Transactions on Magnetics, Vol. 49, No. 6, pp. 2578-2581, 2013

[11] L. Ferraris, F. Franchini, E. Poskovic, "Design optimization of bonded PM BLDC motors with reference to the cogging torque amplitude", 41st Annual Conference of the IEEE Industrial Electronics Society, Yokohama, Japan, pp. 001264-001269, November 9-12, 2015

[12] M. P. Anjana, K. S. Shinoy, J. Joy, "Comparative analysis of surface mounted and tangentially magnetized permanent magnet BLDC motor using finite element method", Annual International Conference on Emerging Research Areas: Magnetics, Machines and Drives, Kottayam, India, pp. 1-5, July 24-26, 2014

[13] C. Carunaiselvane, S. Jeevananthan, "Generalized procedure for BLDC motor design and substantiation in MagNet 7.1.1 software", International Conference on Computing, Electronics and Electrical Technologies, pp. 18-25, Kumaracoil, India, March 21-22, 2012

[14] V. Keloth, M. Mijas, P. A. Manu, P. Thomas, V. M. Menon, R. P. Praveen, "Analysis of cogging torque reduction techniques of a slotless PMBLDC motor", Annual International Conference on Emerging Research Areas: Magnetics, Machines and Drives, Kottayam, India, July 24-26, 2014

[15] Y. Donmezer, L. T. Ergene, "Cogging torque analysis of interior-type permanent-magnet brushless DC motor used in washers", 8th International Symposium on Advanced Electromechanical Motion Systems and Electric Drives Joint Symposium, Lille, France, July 1-3, 2009

[16] P. Bogusz, M. Korkosz, A. Powrozek, J. Prokop, P Wygonik, “An analysis of properties of the BLDC motor for unmanned aerial vehicle hybrid drive", International Conference on Electrical Drives and Power Electronics, Tatranska Lomnica, Slovakia, pp. 458-464, September 2123, 2015

[17] P. Ling, D. Ishak, T. L. Tiang, "Influence of magnet pole arc variation on the performance of external rotor permanent magnet synchronous machine based on finite element analysis", IEEE International Conference on Power and Energy (PECon), Melaka, Malaysia, pp. 552557, November 28-29, 2016

[18] J. H. Choi, J. H. Kim, D. H. Kim, Y. S. Baek, "Design and parametric analysis of axial flux PM motors with minimized cogging torque", IEEE Transactions on Magnetics, Vol. 45, No. 6, pp. 2855-2858, 2009

[19] H. S. Kim, Y. M. You, B. I. Kwon, "Rotor shape optimization of interior permanent magnet BLDC motor according to magnetization direction", IEEE Transactions on Magnetics, Vol. 49, No. 5, pp. 2193-2196, 2013 
[20] M. Sargazi, M. Esmaili, M. Jafarboland, M. Khajavi, "Effect of pole embrace on the cogging torque and unbalanced magnetic forces of BLDC motors", 22nd Iranian Conference on Electrical Engineering, Tehran, Iran, pp. 826-830, May 20-22, 2014 